\title{
Anaplastic Ependymoma in the Cervical Spinal Cord of a Maltese Dog
}

\author{
Yoshiko MICHIMAE $^{1)}$, Takehito MORITA ${ }^{1) *}$, Yoko SUNAGAWA ${ }^{1)}$, Masumi SAWADA ${ }^{1)}$, Yoshiharu OKAMOTO ${ }^{2)}$ and \\ Akinori SHIMADA ${ }^{1)}$ \\ ${ }^{1)}$ Department of Veterinary and Pathology, ${ }^{2)}$ Veterinary Hospital, Faculty of Agriculture, Tottori University, Tottori 680-8553, Japan
}

(Received 27 October 2003/Accepted 19 April 2004)

ABSTRACT. An 8-year and 6-month-old female Maltese dog showed a stoop with rigidity of her cervix and back. Neurologic examination showed loss of proprioception, and deficiency of pain response. Postmortem examination revealed the neoplastic mass replacing the central area in the cervical spinal cord at the level from 4th to 5th segments. Histologically, the mass was composed of neoplastic ependymal cells. The neoplastic cells showed marked atypism, and occasionally formed ependymal rosettes. Based on the morphologic features, the tumor was diagnosed as anaplastic ependymoma. Immunohistochemistry showed that the neoplastic cells were negative for glial fibrillary acid protein, and slightly positive for vimentin and cytokeratin.

KEY WORDS: anaplastic ependymoma, canine, spinal cord.

J. Vet. Med. Sci. 66(9): 1155-1158, 2004

Ependymoma is a rare neoplasm in the central nervous system (CNS), and has been reported in dogs, cats, cattle, horses and some rodents $[8,12]$. In humans, this neoplasm develops commonly in the spinal cord and the fourth ventricle [16], while in animals, the tumor occurs mainly within lateral ventricles, less often in the third or fourth ventricle, and rarely within the central canal of spinal cord [8]. In dogs, only 2 cases have been reported as anaplastic ependymoma in the CNS, one of which was originated from the central canal of lumbar segment $[11,13]$. To our knowledge, anaplastic ependymoma originated from the central canal of the cervical spinal cord has not previously been reported in dogs. This paper describes clinical, radiographic, histopathologic and immunohistochemical features of a case of anaplastic ependymoma found in the spinal cervical segment in a dog.

An 8-year-old and 6-month-old female Maltese dog with an 8-day-history of anorexia and diarrhea was brought to a private veterinary hospital. Neurologic examination showed knuckling of the left anterior limb, loss of proprioception, and deficiency of pain response. Next day, the dog was brought to the Veterinary Teaching Hospital of Tottori University. At that time, the dog showed a stoop with rigidity of her cervix and back. At myelographic examination, the dorsal and ventral lines of contrast medium (iopamidol, JAPAN SCHERING) were not clearly observed in the subdural space forward to the cervical 5th (C5) level, which implied marked swelling of spinal parenchyma resulting in an obstruction of subdural spaces at the anterior levels from C6 (Fig. 1). Six days later, the dog died and necropsied immediately after death.

At necropsy, a gray and brown-color mass replacing the central area of the spinal cord was found at the level from cervical 4 th to 6 th segments. The tumor mass showed expansive growth to the parenchyma of the spinal cord at the

\footnotetext{
* Correspondence to: Morita, T., Department of Veterinary Pathology, Tottori University, 4-101 Minami Koyama-cho, Tottori 680-8553, Japan.
}

level of C5. Hemorrhagic and necrotic foci were scattered in the tumor mass (Fig. 2). Spinal parenchyma of C6 segment was markedly swollen. Both sites of lateral ventricles, third ventricles and mesencephalic aqueducts were mildly dilated. No significant lesions were observed in other visceral organs, except for moderate edema in the lung. Tissue samples were taken from cervical spinal cord, liver, spleen, heart, kidney and lung, and fixed in neutral buffered $10 \%$ formalin for histological examination. They were then dehydrated, embedded in paraffin wax, sectioned at $3 \mu \mathrm{m}$ and stained with hematoxylin and eosin (HE). Immunohistochemistry was performed with labeled streptavidin-biotin (LSAB) method. Rabbit antisera against human glial fibrillary acidic protein (GFAP, prediluted, Dako, Glostrup, Denmark), and mouse monoclonal antibodies against human epidermal keratin (cytokeratin AE1/AE3, 1:20, Dako, Carpinteria, CA) [2] and bovine vimentin (1:20, Chemicon, Temecula, CA) were used as primary antibodies. The reaction products were visualized using the peroxidase and 3,3'diaminobenzidine system. The sections were counterstained with methyl green or hematoxylin. A spinal cord of an 8-month-old dog was used as a control.

Histologically, the mass was composed of neoplastic ependymal cells with large necrotic foci (Fig. 3). The neoplastic cells frequently showed solid or papillary-tubular pattern of growth and had cilia on the surface of the cells (Fig. 4). Infiltrative growth of the neoplastic cells was occasionally observed in the demarcated areas (Fig. 5). The neoplastic cells have ovoid to spindle, deeply chromatic nuclei and indistinct eosinophilic cytoplasm. Also, the neoplastic cells showed apparent cellular atypism and many nuclear mitotic figures (Fig. 6), and there was occasional formation of some ependymal rosettes (Fig. 7). Around the neoplasm, marked degeneration and necrosis of neurons were seen. The vascular endothelial cells were markedly swollen. Immunohistochemically, the neoplastic cells were negative for GFAP, and slightly positive for vimentin and cytokeratin (Fig. 8), while the ependymal cells of the central canal was 

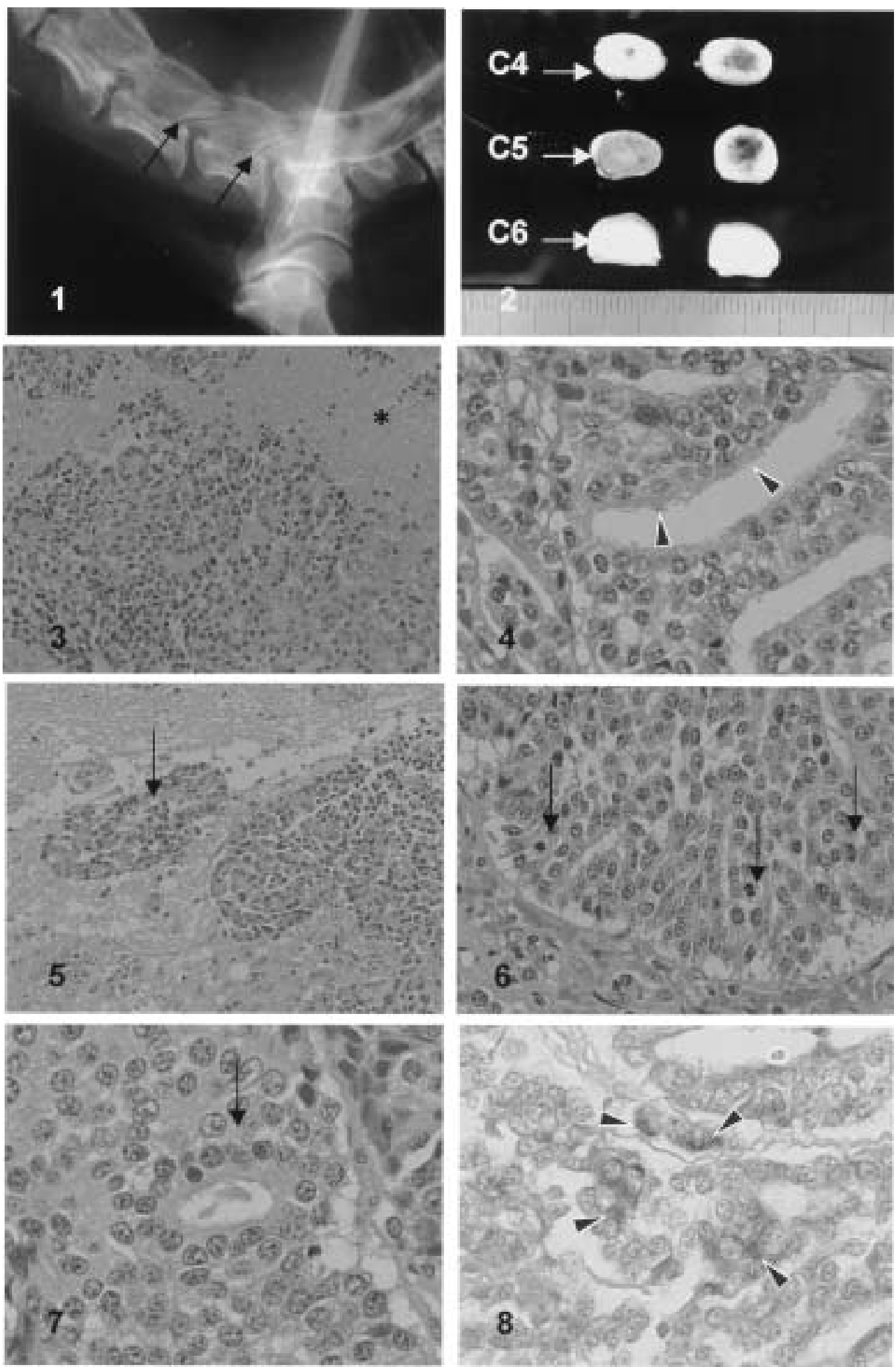
slightly positive for vimentin and negative for GFAP and cytokeratin in a control dog. Astrocytes were positive for GFAP and vimentin. No significant lesions were observed in the other organs, except for hepatocellular glycogen degeneration and pulmonary edema.

Myelographic examination in this case showed marked swelling of spinal cord, and mass lesions such as tumor, granuloma, hematoma or edema would be speculated as a differential diagnosis. Pathologic findings of the present case can be summarized as follows: 1) the cervical segments of the spinal cord exhibited tumor tissue replacing mainly the central area, 2) the neoplastic cells showed solid or papillary-tubular proliferation with some ependymal rosettes, and 3) the neoplastic cells showed extensive necrosis and focal infiltrative growth, together with moderate to marked atypism and many mitotic figures. Based on these findings, this tumor was diagnosed as anaplastic ependymoma [7]. Anaplastic ependymoma is a very rare neoplasm in animals $[8,12]$ and has been reported in two dogs, one occurred within the fourth ventricle [11], and the other within the central canal of lumbar spinal cord [13]. Teuscher et al. [13] has described the first case report of anaplastic ependymomas of the spinal lumbar segments, which showed high cellularity of neoplastic cells, presence of anaplastic cell and many mitotic figures. In dogs, some cases of benign spinal ependymoma have been described $[4,5,17,18]$, and the tumors tended to locate between thoracic and lumbar segments of the spinal cord. In this case, the tumor was located in cervical segment, which may be responsible for neurological signs such as knuckling of left anterior limb, loss of proprioception and deficiency of pain response.

The first differential diagnosis for the present case is anaplastic choroid plexus tumor. Canine choroid plexus tumor most commonly arise in the fourth ventricle [8, 12], whereas this tumor tissue occurred in the cervical segments of the spinal cord. Ependymoma is histologically characeterized by ependymal rosette or vascular pseudorosette, while plexus tumor does not show these features [8, 12]. The second differential diagnosis is primitive neuroectodermal tumor (PNETs), excluding cerebellar origin and neuroblastoma [7]. These tumors have been known to form rosette without cilia, and not to show papillary-tubular growth pattern [8]. The present tumor exhibited papillarytubular growth pattern and apparently showed rosett structures, which are frequently associated with cilia on the surface of the cells. These findings enabled us to exclude a diagnosis of these embryonal tumors.
GFAP immunoreactivity of ependymoma has been reported to be positive in humans, cats, and horses [3, 6, 7], but most canine ependymoma including this case were negative for GFAP $[1,14]$. The reason for the negative finding for GFAP in canine cases is unknown. In the present case, immunoreactivity for vimentin was slightly positive, which was the same as findings reported in other animals $[2,6,10$, 12]. The immunoreactivity for cytokeratin was also slightly positive in the present case, while was negative in the control dog. Immnoreactivity for cytokeratin has also been described to be negative in humans and animals $[1,8,12$, 16], but some reports have demonstrated that occasional cases of human ependymomas were positive for cytokeratin $[9,15]$. The reason for the inconsistency of immunostaining for cytokeratin remains to be elucidated.

\section{REFERENCES}

1. Baumgartner, W. and Peixoto, P.V. 1987. Vet. Pathol. 24: 500503.

2. Cantile, C., Campani, D., Menicagli, M. and Arispici, M. 2002. J. Comp. Pathol. 126: 183-193.

3. Carrigan, M.J., Higgins, R.J., Carlson, G.P. and Naydan, D.K. 1996. Vet. Pathol. 33: 77-80.

4. Chaffee, V.M. 1977. Vet. Med. Small Anim. Clin. 72: 18541857.

5. de Vries-Chalmers Hoynk van Papendrecht, H.R., Vos, J.H. and van Nes, J.J. 1988. Vet. Q. 10: 205-210.

6. Hamaya, K., Doi, K., Tanaka, T. and Nishimoto, A. 1985. Acta Med. Okayama. 39: 453-462.

7. Koestner, A., Bilzer, T., Fatzer, R., Schulman, F.Y., Summers, B.A. and Van Winkle, T.J. 1999. pp. 22-26. In: Histological Classification of Tumor of the Nervous System of Domestic Animals, Second series, Armed Forces Institute of Pathology, Washington, D.C.

8. Koestner, A. and Higgins, R.J. 2002. pp. 707-716. In: Tumors in Domestic Animals, 4th ed.(Meuten, D.J. ed.), Iowa State Press, U.S.A.

9. Kunishio, K., Shiraishi, T., Mishima, N., Satoh, T., Matsumoto, K., Furuta, T., Nishimoto, A. and Taguchi, K. 1991. Neurol. Med. Chir. 31: 859-866.

10. Mckay, J.S., Targett, M.P. and Jeffery, N.D. 1999. J. Comp. Pathol. 120: 105-113.

11. Savage, A., Isa, J.M. and Fischer, W. 1962. Cornell Vet. 52: 68-70.

12. Summers, B.A.,Cumming, J.F. and de Lahanta, A. 1994. pp. 375-379. In: Veterinary Neuropathology (Summers, B.A., Cumming, J.F. and de Lahanta, A. eds.), Mosby, St. Louis, U.S.A.

13. Teuscher, E. and Cherrstrom, E.C. 1974. Schweiz. Arch. Tier-

Fig. 1. Myelographic finding. The dorsal and ventral lines of contrast are not clearly observed in the space forward to the C5 and C6 levels (arrows).

Fig. 2. Gross findings of the cut surface of C4 to C6 segments. Gray and brown-color lesions replacing the central area of the spinal cord are found in the C4 and C5 segments. Spinal parenchyma of C6 segment is markedly swollen.

Fig. 3. The neoplastic cells show extensive necrosis (asterisk) and solid growth pattern. HE. $\times 185$.

Fig. 4. The neoplastic cells show tubular pattern of growth and cilia on the surface of the cells (arrowheads). HE. $\times 368$.

Fig. 5. In the demarcated area, infiltrative proliferation of the neoplastic cells is found (arrow). HE. $\times 185$.

Fig. 6. The neoplastic cells show marked atypism and some mitotic figures (arrows). HE. $\times 368$.

Fig. 7. The neoplastic cells show formation of an ependymal rosette (arrow). HE. $\times 560$.

Fig. 8. The cytoplasms of neoplastic cells are slightly positive for cytokeratin (arrowheads). Immunostaining of cytokeratin. $\times 560$ 
heilk. 116: 461-466.

14. Vandevelde, M., Fankhauser, R. and Luginbuhl, H. 1985. Acta Neuropathol. 66: 111-116.

15. Vege, K.D., Giannini, C. and Scheithauer, B.W. 2000. Appl. Immunohistochem. 8: 25-31.

16. Wiestler, O.D., Schiffer, D., Coons, S.W., Prayson, R.A. and Rosenblum, M.K. Ependymoma. 2000. p. 72. In: WHO Classi- fication of Tumors Pathology and Genetics of Tumors of the Nervous System (Kleihues,P. and Cavenee,W.K. eds.), IARC Press, Lyon, France.

17. Wright, J.A. 1985. J. Comp. Pathol. 95: 549-557.

18. Zachary, J.F., O'rien, D.P. and Ely, R.W. 1981. Vet. Pathol. 18: 697-700. 